\title{
In memory of Professor Enrico Mihich: Editor-in-Chief of Cancer Immunology, Immunotherapy 1982-2012
}

\author{
Graham Pawelec ${ }^{1} \cdot$ Suzanne Ostrand-Rosenberg $^{2}$
}

Published online: 11 March 2017

(C) Springer-Verlag Berlin Heidelberg 2017

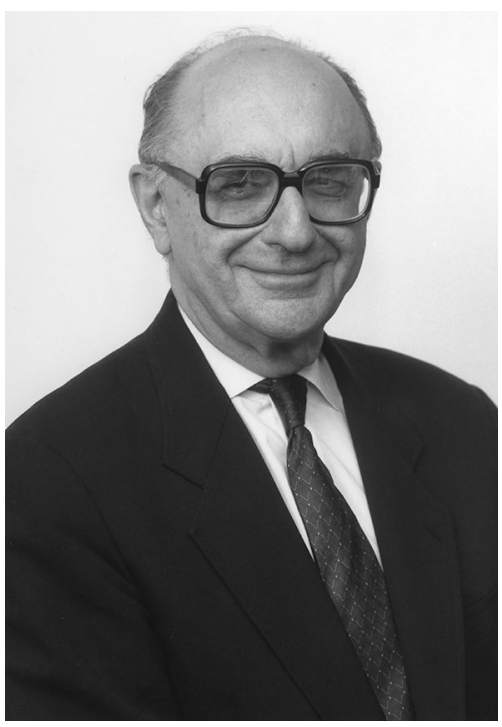

It is with very great sadness that the editors and publishers of Cancer Immunology, Immunotherapy announce the death of former co-Editor-in-Chief Professor Enrico (Henry) Mihich on 29th December, 2016. Prof. Mihich was one of the first to show that the anti-tumour effects of some types of chemotherapeutic agents were not only dependent on drug-induced cancer cell death but to a large extent on their immunomodulatory activity. A pioneer of

Graham Pawelec

graham.pawelec@uni-tuebingen.de

1 Second Department of Internal Medicine, University of Tübingen Medical School, Tübingen, Germany

2 Department of Biological Sciences, University of Maryland Baltimore County, Baltimore, MD, USA the idea that chemotherapy is not merely cytotoxic, he was appointed as an Editor-in-Chief of our Journal-by far the oldest specialist journal in this field-in 1982.

Contributing many innovative approaches to publishing cutting edge work in Cancer Immunology, Immunotherapy and in his own research on anti-cancer drugs, he markedly influenced the development of both. Prof. Mihich joined the Roswell Park Cancer Institute (RPCI) in Buffalo, New York in 1957, at a time when chemotherapy itself was emerging as a viable cancer treatment. By 1976, the Grace Cancer Drug Center (GCDC) directed by Prof. Mihich had developed into an internationally recognized center for basic and translational cancer research, with around 200 researchers and students. Prof. Mihich was thus a major guiding light in cancer research at this formative time, for the benefit of science and patients both. The GCDC's focus on fundamental as well as translational work contributed essential knowledge on drug resistance, tumour cell heterogeneity and the importance of the microenvironment and contributed to the realization that host immunity can confer effective anti-cancer protection.

Our deepest sympathies are with Dr. Mihich's family. An obituary to record and celebrate his many accomplishments and attributes will be published by the Journal in due course.

Graham Pawelec

Suzanne Ostrand-Rosenberg (Co-Editors-in-Chief, Cancer Immunology, Immunotherapy) 